\title{
Análisis de la restricción a las importaciones del sector automotriz en el Ecuador periodo 2010 - 2015 y su impacto en la economía
}

\section{Analysis of the restriction on imports of the automotive sector in Ecuador, period 2010 - 2015 and its impact on the economy}

Lucía Magdalena Pico Versoza

Universidad Internacional del Ecuador, Ecuador

Ricardo Rafael Coello Yagual

Universidad Tecnológica Empresarial de Guayaquil

Autor para correspondencia: lupicove@ internacional.edu.ec, ricardo_mvc@ hotmail.com. Fecha de recepción: 01 de Febrero de 2016 - Fecha de aceptación: 25 de Febrero de 2017

\section{Resumen}

El presente estudio analiza las políticas adoptadas por el gobierno de turno, mismas que sitúan al país en una restricción de importaciones que se presentan en tres formas: salvaguardias, recargos específicos y cupos de importación. El sector parte del estudio es la industria automotriz, que en los últimos años ha sufrido cambios en su demanda y oferta, evidenciando la gran cantidad de divisas que salen continuamente del país lo cual a su vez perjudica a la actual Balanza Comercial, siendo este uno de los principales indicadores de la economía del país. Por otra parte, se hace referencia la contraparte, en la respuesta del gobierno impulsando el desarrollo productivo como eje estabilizador de una política económica que a su vez conlleve dinamismo en la economía.

Palabras clave: Restricción; importaciones; sector automotriz

\begin{abstract}
The present study analyzes the policies adopted by the current government, which place the country in an import restriction that comes in three forms: safeguards, specific surcharges and import quotas. The sector part of the study is the automotive industry, which in recent years has undergone changes in its demand and supply, evidencing the large amount of currencies that continuously leave the country which in turn damages the current Trade Balance, this being one Of the main indicators of the country's economy. On the other hand, the counterpart is referred to in the government's response by promoting productive development as the stabilizing axis of an economic policy which in turn leads to dynamism in the economy.
\end{abstract}

Key words: restriction; imports; automotive industry 


\section{Introducción}

En los últimos años el Ecuador ha sufrido una constante coyuntura negativa en el sector externo llevando a que los organismos reguladores de la política económica consideren adoptar medidas restrictivas a partidas de productos que ocasionan la salida de divisas del país. Gran parte de este acontecimiento se debe a la caída del precio del petróleo y constante déficit presupuestario. Es por esto, que el Comité de Comercio Exterior ha decidido reforzar esta medida para controlar el déficit en balanza comercial del país. (Banco Central del Ecuador, 2015).

Son muchos los sectores de la economía que se han visto afectados, entre ellos el sector automotriz, industria que se abordara en este análisis. Este sector tiene una participación importante en la economía del país debido a los ingresos que genera en las diferentes ramas productivas que involucra esta actividad, impulsando de manera directa e indirecta a otras industrias del sector productivo como por ejemplo: siderúrgica, metalúrgica, metalmecánica, minera, petrolera, petroquímica, plástico, vidrio, electricidad, robótica e informática, las cuales son de gran importancia en la elaboración de los vehículos.

En el Ecuador, el sector automotriz generalmente ha mantenido una importante participación en la economía debido a los ingresos que se generan en las distintas ramas del sector productivo en las que se involucra esta actividad, y que a su vez da impulso hacia las otras industrias mencionadas en el párrafo anterior. Es así, como el sector automotriz integra a diferentes actores, tanto para las firmas autopartistas proveedoras de partes y piezas; así como para las ensambladoras que son las firmas que imponen los estándares productivos de la cadena.

"El sector automotor tiene una participación importante en la economía del país debido a los ingresos que genera en todas las actividades económicas directas e indirectas que involucra". (Pro Ecuador, Dirección de Inteligencia Comercial e Inversiones, 2013)

A través del censo realizado por el INEC para el año 2014 existían 29.068 establecimientos que se dedican a actividades relacionadas con el comercio de esta industria, es decir el: "70 \% dedicados al mantenimiento y reparación de vehículos y el 30\% venta de partes, piezas y accesorios de vehículos y venta al por menor de combustibles y vehículos". (Carlos Quisiguiña, Banco Central del Ecuador, 2016)

La metodología a usar en la presente investigación es exploratoria ya que se analizarán estadísticas que permitan analizar la incidencia de las medidas restrictivas, así como las razones que impiden el desarrollo de la industria automotriz. A través de la obtención de la información el análisis se enfoca en investigar y evaluar las situaciones específicas en que se ha visto afectado el sector automotriz, así como conocer los riesgos a los que se enfrenta este sector. Se pretende crear un escenario claro y específico que sirva de análisis de las decisiones que afectan a la industria automotriz y su desarrollo en la economía.

Para abordar el tema y analizarlo a fondo es necesario tener claro varios conceptos, por ejemplo observar las políticas como reglas, según Julián Pérez Porto y Ana Gardey (2014), en su artículo menciona la definición de regla como normativas o preceptos que deben respetarse. Por 
lo general, las reglas surgen de un acuerdo entre dos partes: la que ordena o regula y el sujeto pasivo, el cual es el que obedece las políticas, en aduanas ocurre algo similar, así las políticas que instauren son aprobadas por organismos superiores que evalúan la situación del país y del comercio.

Existen barreras arancelarias y no arancelarias. Según Pro Ecuador "las barreras arancelarias son tarifas oficiales que se fijan y cobran a los importadores y exportadores en las aduanas de un país", esto se aplica para la entrada o salida del país, en el caso de Ecuador solo se cobran tasas arancelarias por la importación más no por la exportación. Mientras que las barreras no arancelarias son "las disposiciones gubernamentales que obstruyen el ingreso libre de mercancías a un país determinado, generando requisitos de ingreso a los productos o servicios, así también reglas o ciertas características”.

En el caso de la industria automotriz se han aplicado las siguientes medidas: incremento en aranceles y cupos de importación. Esta política adoptada responde a una necesidad de restricción en las importaciones de partidas que generan gran cantidad de salida de divisas en el país, situación que en ámbito económico y comercial se explicará a detalle en los siguientes párrafos.

El 8 de enero del 2016 el Servicio Nacional de Aduanas del Ecuador (SENAE) señalo que los vehículos importados deben cumplir con la documentación de control previo cuando lleguen al país, entre las resoluciones que se añadieron a través del Comité de Comercio Exterior fue establecer cupos de importación, el cual establece año a año la revisión y la reducción de los montos de importación del sector automotriz. Así:

"hasta el 2015, el cupo para los autos importados era de USD 300 millones anuales, que se repartía entre 46 importadores. Para este 2016, según la Resolución 050 del Comité de Comercio Exterior (COMEX), el cupo bajó a USD 280 millones" (El Comercio, actualidad, 2016)

También se aplicó una documentación requerida que los importadores deben presentar al ingresar los autos al país es para cumplir con el Reglamento Técnico Ecuatoriano 034 del INEN. Los ensambladores, por su parte además de este reglamento deben presentar el Registro de Importador del Ministerio de Industrias. El Servicio Nacional de Aduanas (SENAE) indicó que:

"las personas jurídicas que tengan Registro Único de Contribuyente (RUC) registrado con la actividad comercial de venta de vehículos nuevos y usados; y, vayan a realizar la importación de vehículos deberán solicitar a Aduana su incorporación al registro Como importador en Ecuapass”. (Pro Ecuador, Dirección de Inteligencia Comercial e Inversiones, 2013)

A continuación se presenta un breve análisis de las importaciones en los periodos citado en la presente investigación:

En el año 2010 la importación de vehículos llegó a 1300 millones de dólares. 
"Según los datos oficiales, los autos y el equipo de transporte importados son uno de los sectores que presentaron un crecimiento de más del $60 \%$ en la balanza comercial. De hecho registran un incremento superior a 639 millones de dólares”. (Diario La Hora, Economía, 2011)

Este incremento se reflejó en el aumento de las ventas de autos durante el año 2010. Según estimaciones de la firma Market Watch, en ese año se "despacharon cerca de 125 mil unidades, de los cuales el $40 \%$ fue abastecido por la industria local y el $60 \%$ fue importado". (Diario La Hora, Economía, 2011)

En el año 2011 el panorama se presenta con la premisa de que para la asignación de unidades a importar el gobierno tomó como referencia las importaciones del año anterior. Esto representó una reducción del 35,6\% frente a lo que el sector trajo en el periodo comparado, es decir los importadores estuvieron impedidos de ingresar 27.286 unidades. La restricción en dólares representó una disminución del 30\% del valor FOB (sin contar con flete y aranceles) sobre el monto importado en el 2010. Así, General Motors (Chevrolet) tuvo un rubro de \$63, 49 millones para importar este año 6.511 carros; Neohyundai (Hyundai) un monto de \$82,73 millones para 10.766 unidades; Aekia (Kia) $\$ 33,35$ millones para 4.373 unidades, entre las principales marcas.

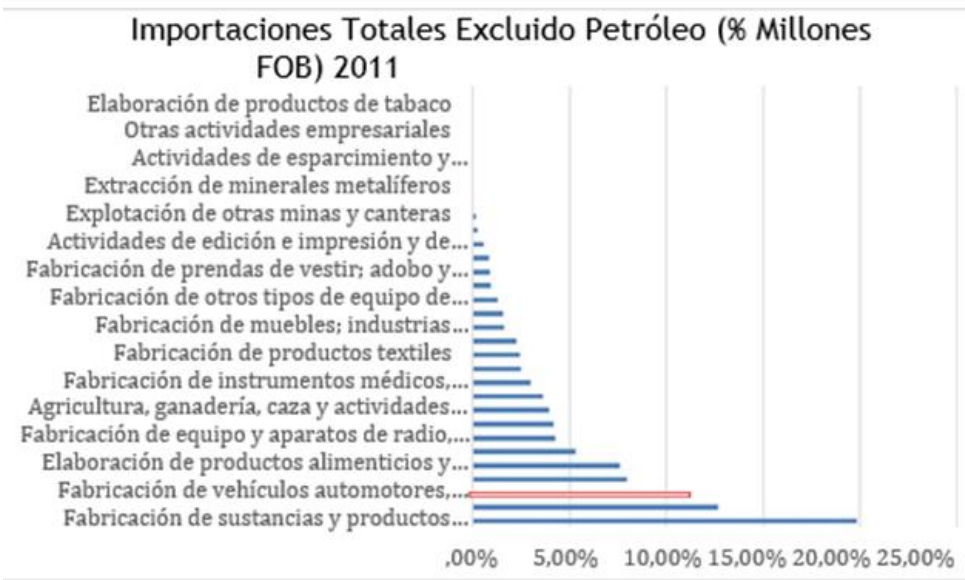

Gráfico 1. Importaciones Totales Excluido Petróleo (\% Millones FOB) 2011 Fuente: http://indestadistica.sni.gob.ec

Tal como se evidencia en el gráfico No. 1 las importaciones de vehículos fueron considerables en relación a otros sectores, situación que llevó a generar comentarios en el sector, como por ejemplo Gloria Navas, Presidenta de la Asociación de Empresas Automotrices del Ecuador (AEADE) indicó en una entrevista a un diario: "la reducción fue muy fuerte considerando que por dos años seguidos estuvimos sujetos a una reducción" y, añadió: "esto sin dudas podría reducir las plazas de trabajo en el sector y, su aporte al fisco en términos de impuestos y tasas" (Diario La Hora, País , 2015)

En el periodo anterior el cupo había sido de 48.179 unidades, este monto se repartió entre 38 importadores. Para ese nuevo periodo, la cifra varió levemente porque se incorporaron 12 compañías adicionales, pero se mantuvieron las cuotas para las firmas que ya fueron consideradas. En el año 2012, el Comité de Comercio Exterior (COMEX) aprobó una restricción 
para el ingreso de vehículos importados al país y CKD o partes para su ensamblaje local. Además existió una reducción considerable en los cupos de importación con respecto al año anterior. Luis Eduardo Crespo, presidente de la Comisión Sectorial Automotriz de la Cámara de Comercio de Guayaquil, aseguró que: “esa resolución cambia las reglas del juego y pone en riesgo el abastecimiento de algunas marcas”. (Diario El Universo, Economía, 2012). Es así, que de acuerdo a los datos publicados en aquel entonces por la Asociación Ecuatoriana Automotriz, indicó que en promedio las marcas tuvieron una reducción en la importación de vehículos en $55 \%$ en cuanto a unidades con respecto al año anterior y en un $52 \%$ en cuanto a montos.

\section{Importaciones Totales Excluido Petróleo (\% Millones FOB) 2012}

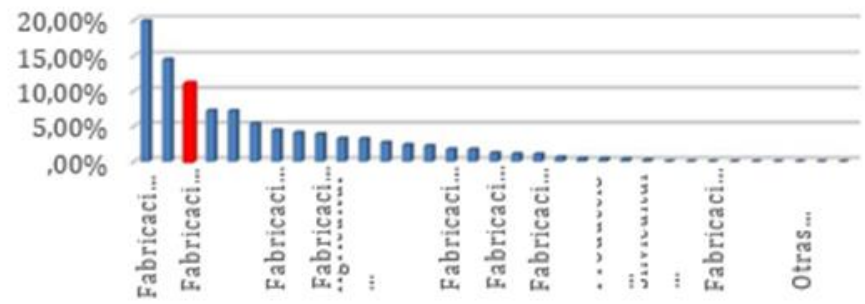

Gráfico 2. Importaciones Totales, excluido Petróleo (\% Millones FOB) 2012Fuente: http://indestadistica.sni.gob.ec

Por otro lado, la venta de automóviles en el país: "durante 2012 sumó alrededor de 121.803 unidades. Observándose, una contracción de 18.000 unidades con respecto al 2011 por las medidas de protección de importaciones". (Pro Ecuador, Dirección de Inteligencia Comercial e Inversiones, 2013). En el año 2013, en Ecuador se comercializaron 52 marcas de vehículos, de los cuales 21 correspondieron a países asiáticos como China, Japón, Corea del Sur e India, según las cifras presentadas por la Asociación de Empresas Automotrices del Ecuador (AEADE).

Diego Luna, Presidente de la Asociación de Empresas Automotrices del Ecuador (AEADE) indicó que "el sector vive un estancamiento de ventas desde el 2012", y añade: "Por la aplicación de una política de cuotas, cupos y medidas arancelarias, los segmentos de automóviles, vans (furgoneta) y buses registraron sus niveles de ventas más bajos en los últimos cuatro años" (Diario El Comercio, Actualidad, 2013). Siguiendo el texto de la investigación encontramos que cerca del $40 \%$ de las marcas de automotores que circulan por el Ecuador proviene del continente Asiático, de este grupo las tres mayores ventas son por parte de Kía: 12.300 unidades, Hyundai: 9629 unidades y Nissan con 6576 unidades de vehículos. 


\section{Ventas porcentuales de las marcas Asiáticas \\ en el Ecuador año 2013}

- KIA

— HYUNDAI

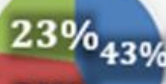

$34 \%$

Gráfico 3. Ventas porcentuales de las marcas Asiáticas en el Ecuador año 2013 Fuente: Elaboración propia

En el año 2014 y 2015, el Comité de Comercio Exterior (COMEX) dio a conocer el lunes 5 de enero del 2015 un nuevo recorte en los cupos de importación de vehículos para el país, a través de la publicación de la resolución 049-2014, aprobada el 29 de diciembre del 2014, resolvió:

Artículo 1. Prorrogar hasta el 31 de diciembre de 2015, la vigencia de Resoluciones del COMEX Nos. 65 y 66 del año 2012, y 011 - 2014, así como de sus respectivas reformas, de conformidad con los Anexos 1 y 2 de la presente resolución. (Ver Anexo 1 y Anexo2)

Artículo 2. Conceder un cupo para la importación de vehículos eléctricos de hasta 1000 unidades o 25 millones FOB, lo que suceda primero.

La resolución entró en vigencia a través del Registro Oficial, esto ocasionó una reducción en los cupos de importación de hasta un $57 \%$ con respecto al año anterior, la medida que dio origen a los cupos se tomó en junio del 2012:

"Al comparar los cupos de esa época con los cupos que están vigentes para este año, se registran importantes reducciones". Por ejemplo, para el importador Automotores y Anexos S.A Ayasa, que maneja las marcas Nissan y Renault, el cupo de importación en monto se redujo de USD 92 millones a USD 50 millones" . (Diario El Comercio, Actualidad, 2015). Es decir, un recorte del $46 \%$.

Así también para negocios automotrices Neo Hyundai S.A., que comercializaba "los vehículos de la marca Hyundai, el cupo bajó de USD 82 millones a USD 46 millones. Es decir, un recorte del 44\%”. (Diario El Comercio, Actualidad, 2015)

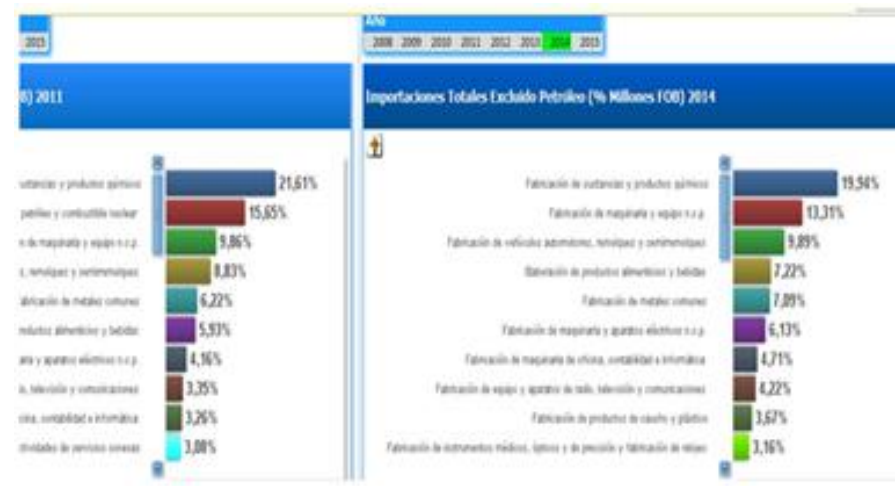

Gráfico 4. Importaciones totales excluido Petróleo (\% Millones FOB) 2014 
Fuente: http://indestadistica.sni.gob.ec

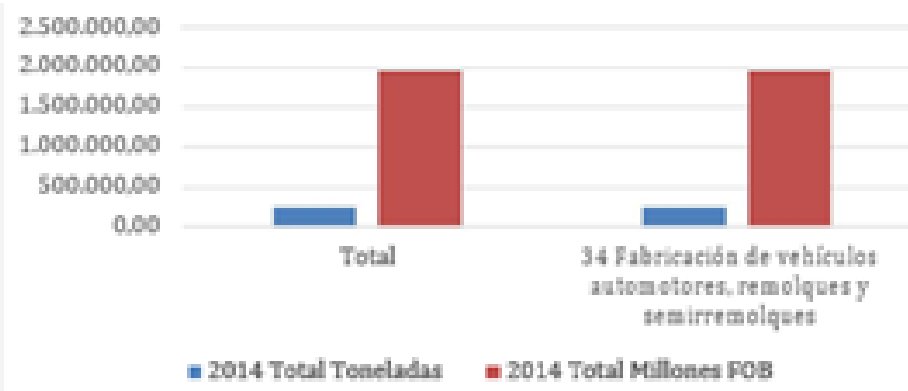

Gráfico 6. Importación sector automotriz en el año 2014 Fuente: http://indestadistica.sni.gob.ec

\section{Coyuntura Económica y Balanza Comercial del Ecuador}

El análisis año a año de las importaciones que permitió la política económica adoptada por el Ecuador en relación a la industria automotriz nos permite determinar que es producto de una serie de situaciones que afectaron a la economía del país y su situación comercial. Para analizar la coyuntura económica del país, tendríamos que considerar todas las variables más relevantes, tales como la demanda, el tipo de interés, el índice general de precios, la disponibilidad y el costo de la mano de obra, así como el déficit presupuestario y su incidencia en la Balanza de pagos.

En el gráfico a continuación se muestra el análisis realizado por el Centro de Estudios Latinoamericanos (CESLA) quien indica la tendencia que sufren las principales variables que forman parte de la situación económica del país y la tendencia que generan.

\begin{tabular}{|c|c|c|c|c|}
\hline \multirow[t]{2}{*}{ ECONOMÍA REAL } & \multicolumn{2}{|l|}{ Último Dato } & \multirow[t]{2}{*}{ Anterior } & \multirow{2}{*}{$\begin{array}{l}\text { TENDENCIA } \\
\text { ANUAL * }\end{array}$} \\
\hline & Fecha & Valor & & \\
\hline PIB (\% Crecimiento) ${ }^{* \cdots}$ & VI TRIM-14 & 0,5 & 1,4 & BAJA \\
\hline Precios al Consumo (IPCA) & mar-15 & 3,8 & 3,1 & ALZA \\
\hline Balanza Cta. Cte. (M.M.S.) & feb-15 & 9,4 & 35,1 & BAJA \\
\hline $\begin{array}{l}\text { Petróleo (Var. Export. Acum } \\
\text { Barriles) }\end{array}$ & mar-15 & 4,8 & $-4,9$ & ALZA \\
\hline Reservas (M.M.S.) ${ }^{* *}$ & feb-15 & $-14,2$ & 2,8 & BAJA \\
\hline $\begin{array}{l}\text { IaversiónExtranjera } \quad \text { Directa } \\
\text { (M.S.)*** }\end{array}$ & III TRIM-14 & 330 & 142 & ALZA \\
\hline Tasa de Paro & dic-14 & 4,5 & 5,6 & BAJA \\
\hline Deuda Externa Pública (M.M.S.) & ene-15 & 36,6 & 18,8 & ALZA \\
\hline
\end{tabular}

Cuadro No. 1. Indicadores de Coyuntura Económica Fuente: CESLA (Centro de Estudios Latinoamericanos)

Es importante considerar que dentro del diagnóstico de las restricciones a las importaciones de vehículos, y también se podría comprender de mejor forma la evolución que ha tenido este sector dentro de la economía ecuatoriana, es decir comprender la situación actual, establecer que existe una restricción, y que debe generarse otra alternativa que sirva de apoyo al desarrollo del mercado en este sector. 
La finalidad de las medidas restrictivas mencionadas anteriormente, responden también al objetivo que se relaciona específicamente con la reducción del déficit en la Balanza Comercial. Esta medida suponía dos aspectos relevantes:

En el 2010, la importación de vehículos llegó a 1300 millones de dólares. Según los datos oficiales, los autos y equipo de transporte importados fueron uno de los sectores que presentaron un crecimiento de más del $60 \%$ en la balanza comercial de aquel entonces, de hecho, se registró un incremento superior a 639 millones de dólares.

\begin{tabular}{|c|c|c|c|}
\hline \multicolumn{4}{|c|}{ 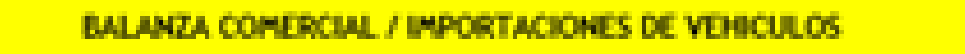 } \\
\hline AHัธ & $\begin{array}{l}\text { Whbugls if } \\
\text { vaktLos }\end{array}$ & $\begin{array}{c}\text { 4 } \mathrm{CL} \\
\text { INATTACKA }\end{array}$ & ME CECAECHEHTO \\
\hline 2011 & 75000 & 1004 & 0 \\
\hline 9012 & t407 & $\mathrm{m}_{1} \mathrm{H}$ & $-14,44$ \\
\hline 1013 & 5455 & 74,944 & $-75,145$ \\
\hline 9014 & 517 & 74,914 & $-25,94$ \\
\hline 2015 & 4042 & bint & $-1 P_{1} T_{k}$ \\
\hline
\end{tabular}

Cuadro No. 2. Balanza Comercial / Importaciones de vehículos Fuente: Elaboración propia

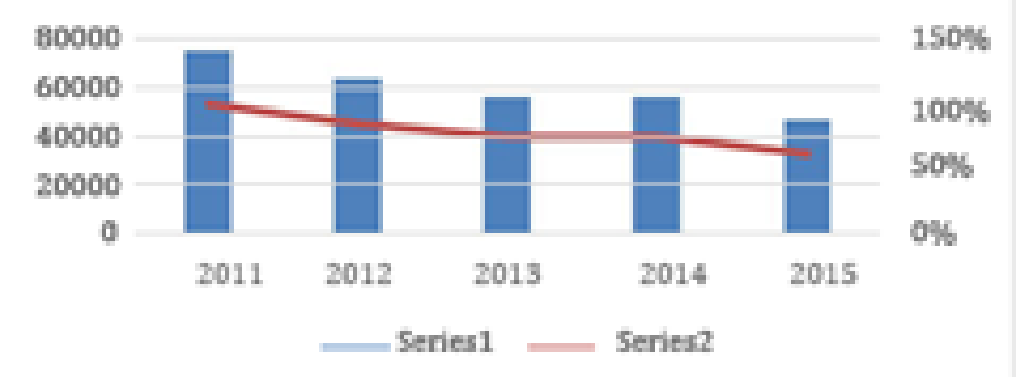

Gráfico 7. Importaciones de vehículos en decrecimiento año a año (2010 - 2015) Fuente: Elaboración propia

El sector automotriz ecuatoriano se había mantenido en crecimiento hace algunos periodos atrás, y el incremento de unidades adquiridas también crecía según las necesidades del consumidor, sin embargo las nuevas leyes y medidas restrictivas favorecieron a un escenario donde no es posible seguir creciendo dadas las limitaciones del sector.

El análisis muestra la reducción de costos como alternativa que puede mantener a las empresas y unidades de negocio en el sector automotriz, con economías y finanzas saludables a pesar de los escenarios que se presentan en el país.

\section{Comercio Internacional}

El comercio internacional del Ecuador con el resto del mundo en el capítulo sobre la importación de vehículos ha tenido una contracción que ha afectado a la economía nacional. En los primeros meses del año 2015 se vendieron 32.920 vehículos entre importados y ensamblados 
en el Ecuador, esto representó “el 39,4 \% del cupo permitido de ese año para la importación de carros terminados, partes y piezas (CKD) para ensamblar, que llegó a 83.438 unidades". (Diario El Universo, Noticias, 2015). El mayor problema de la reducción de esos cupos en relación al 2014, es porque el cupo total de importación que hubo fue de "49.132 unidades de vehículos, en tanto para el 2015 será de 22.277, lo que representa el 53\% menos”. (Diario El Universo, Noticias, 2015)

Según Jaime Cucalón, Presidente de la Asociación Ecuatoriana Automotriz (AEA), el mayor problema que existió fue que el cupo de ese año fue 300 millones, el cual "se dividió para 46 importadores, al empezar el 2016 el cupo se redujo a 280 millones, y fueron divididos en los cuatro trimestres" (Diario El Comercio, 2016). Siguiendo la línea del análisis, el Señor Cucalón indicaba que en los primeros meses del 2016 al menos 150 vehículos estuvieron en la aduana que no podían ingresar al país por falta de cupo, que recién entre abril y junio lo pudieron hacer.

En otra carta, con fecha 29 de enero, ambos gremios advirtieron que las nuevas condiciones impuestas en principios del 2016 afectarían el desarrollo de las actividades normales del gremio, según el autor esta "se redujo a mediados del 2015 en un $62 \%$ en comparación con el 2010” (Diario El Universo, Noticias, 2015). Con ello coincide la Cámara de la Industria Automotriz Ecuatoriana (CINAE) que también tiene cupos para importaciones, pero no trimestrales, a través de su Director Ejecutivo Diego Molina, el cual indicaba que los cupos afectaron a la industria automotriz, ya que el encadenamiento no existió y tampoco hubo niveles adecuados de competitividad (Diario El Universo, Noticias , 2015).

En el 2012 la producción de la industria alcanzó las 79.616 unidades de vehículos, en cambio el 2015 bajó a 48.926 unidades de vehículos. En el 2016 se sumó otro factor adicional a la caída de la demanda (Diario El Comercio, Actualidad, 2015); según datos de la Asociación de Bancos Privados del Ecuador (ABPE) el 22\% de las personas que solicitaron un crédito pre aprobado a la banca para la compra de vehículos desistió del mismo por temor a perder su empleo (Diario El Comercio, Economía, 2016).

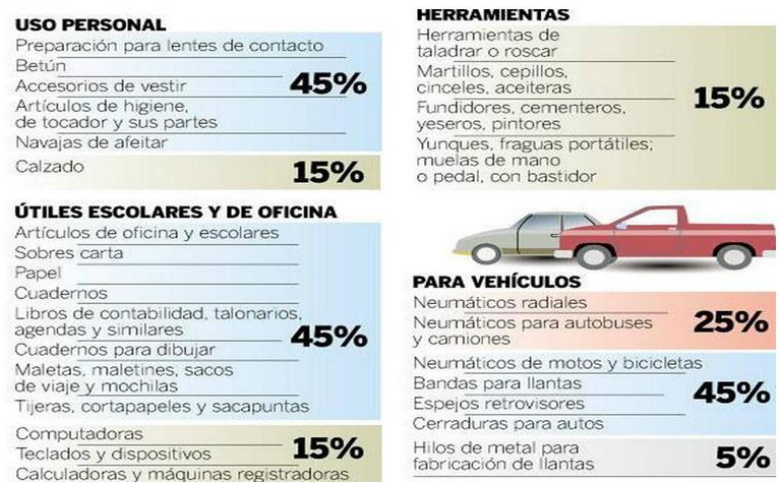

Cuadro No. 3 Aranceles para productos importados 2016 Fuente: Diario el Universo

La sub partida a los vehículos según Resolución No. 050 - 2015 del pleno del COMEX, que está vigente desde el 01 de Enero del 2016 indicaba los productos a los cuales condiciona: 
Los vehículos motorizados de transporte terrestre de hasta 3,5 toneladas, los tricares y los cuadrones están gravados con el Impuesto a los Consumos Especiales (ICE). Para su cálculo se utiliza la base imponible que es el resultado de adicionar el $25 \%$ al valor Ex Aduana, que es el resultado de sumar al valor CIF, los impuestos, aranceles, tasas, derechos, recargos y otros gastos que figuren en la declaración de importación y en los demás documentos pertinentes (http://www.sri.gob.ec/de/10134)

\section{Vehículos motorizados de transporte terrestre de hasta 3.5 toneladas de carga, conforme el siguiente detalle:}

- Vehículos motorizados cuyo precio de venta al público sea de hasta $\$ 20.000$ - 5\%.

- Camionetas, furgonetas, camiones y vehículos de rescate cuyo precio de venta al público sea de hasta $\$ 30.000-5 \%$.

- Vehículos motorizados, excepto camionetas, furgonetas, camiones y vehículos de rescate cuyo precio de venta al público sea superior a $\$ 20.000$ y de hasta $\$ 30.000-10 \%$.

- Vehículos motorizados, cuyo precio de venta al público sea superior a $\$ 30.000$ y de hasta $\$ 40.000-15 \%$.

- Vehículos motorizados, cuyo precio de venta al público sea superior a $\$ 40.000$ y de hasta $\$ 50.000-20 \%$.

- Vehículos motorizados, cuyo precio de venta al público sea superior a $\$ 50.000$ y de hasta $\$ 60.000-25 \%$.

- Vehículos motorizados, cuyo precio de venta al público sea superior a $\$ 60.000$ y de hasta $\$ 70.000-26 \%$.

- Vehículos motorizados, cuyo precio de venta al público sea superior a $\$ 70.000$ - 32\%.

\section{Vehículos motorizados híbridos o eléctricos de transporte terrestre de hasta 3,5 toneladas de carga, conforme el siguiente detalle:}

- Vehículos híbridos o eléctricos cuyo precio de venta al público sea de hasta \$35.000 $0 \%$. Vehículos híbridos o eléctricos cuyo precio de venta al público sea superior a $\$ 35.000$ y de hasta $\$ 40.000-8 \%$.

- Vehículos híbridos o eléctricos cuyo precio de venta al público sea superior a \$40.000 y de hasta $\$ 50.000$ - $14 \%$.

- Vehículos híbridos o eléctricos cuyo precio de venta al público sea superior a \$50.000 y de hasta $\$ 60.000$ - $20 \%$.

- Vehículos híbridos o eléctricos cuyo precio de venta al público sea superior a $\$ 60.000$ y de hasta $\$ 70.000-26 \%$.

- Vehículos híbridos o eléctricos cuyo precio de venta al público sea superior a $\$ 70.000$ 32\%. Fuente: (Senae, SRI, 2007)

Esta información se complementa con la ley reformatoria para la equidad tributaria del Ecuador, publicada en el tercer registro oficial No. 242, del 29 de diciembre del 2007.

Las importaciones de vehículos automóviles y demás vehículos terrestres, sus partes, piezas y accesorios, clasificables en el Capítulo 87 y en la sub partida 9808.00.00.94 del Arancel 
Nacional de Importaciones, con excepción de las partidas 87.12.00.00.87.13; se regirán por las siguientes disposiciones:

a) Se permite la importación de vehículos automóviles, y demás vehículos terrestres, siempre y cuando sean nuevos y su año modelo corresponda al año en que se realice la importación o al año siguiente de la importación. El año modelo de vehículo se verificará por el número de identificación del vehículo (VIN).

Para la determinación del año en que se realice la importación de los vehículos señalados, se considerará la fecha de embarque.

No se consideran como nuevos aquellos vehículos cuyos documentos señalen otra condición.

b) Se permite la importación de partes, piezas y accesorios de los vehículos automóviles, y demás vehículos terrestres, siempre y cuando sean nuevos.

c) Para efectos de proteger el medio ambiente, las importaciones amparadas en esta Resolución, deberán cumplir con todas las normas aplicables para su protección vigentes en el Ecuador, y,

d) Los vehículos automóviles y demás vehículos terrestres que ingresen al país con el propósito de cumplir contratos de obras públicas bajo el Régimen de Importación Temporal con Reexportación en el mismo estado y que soliciten cambio de Régimen a Importación a Consumo, serán considerados como nuevos, siempre que, al momento de haber ingresado a éste Régimen Especial, hayan cumplido con lo estipulado en el literal a) de la presente Resolución.

Artículo 3.- Se permite, la libre importación de equipo caminero, equipos agrícolas, sus componentes y accesorios, usados, siempre que su año modelo de fabricación corresponda a los últimos quince años anteriores al año de importación. Se incluye la sub partida arancelaria 8704.10.00.00.90 entre las partidas y sub partidas de libre importación de equipo caminero inmersas en este artículo.

Artículo 4.- Se permite la importación de vehículos especiales, usados y donados a favor de instituciones públicas o privadas sin fines de lucro, cuya función esté relacionada con las actividades que realizan las entidades beneficiarias. Los vehículos mencionados en el inciso anterior no podrán ser objeto de traspaso de dominio, dentro de los cinco años sub siguientes al de su nacionalización; debiendo la Autoridad Nacional de Tránsito, registrar la correspondiente prohibición de enajenar.

Artículo 5. - Para los casos de donaciones, las instituciones públicas o privadas sin fines de lucro, que vayan a beneficiarse de donaciones de vehículos automotores de uso especial, presentarán ante el Servicio Nacional de Aduanas del Ecuador, junto con la solicitud de exoneración de los tributos al comercio exterior, los siguientes documentos: 
- Copia certificada del convenio de donación, debidamente legalizado por el Cónsul del Ecuador en el país de origen, en el que conste la especificación de que el vehículo donado es compatible con las actividades que realiza la institución beneficiaria, y,

- Copia certificada de los estatutos de la entidad beneficiada, aprobados por el Ministerio del ramo respectivo.

Adicionalmente, durante el trámite de nacionalización respectivo: "la autoridad aduanera deberá verificar que se cumpla la revisión técnica vehicular por parte de la Autoridad Nacional de Tránsito", tal como lo establece el Art. 213 de La Ley Orgánica de Transporte Terrestre, Tránsito y Seguridad Vial.

En 2011 el mercado sudamericano registró un crecimiento promedio de 18.5\%. Los mercados que tuvieron mayor crecimiento fueron:

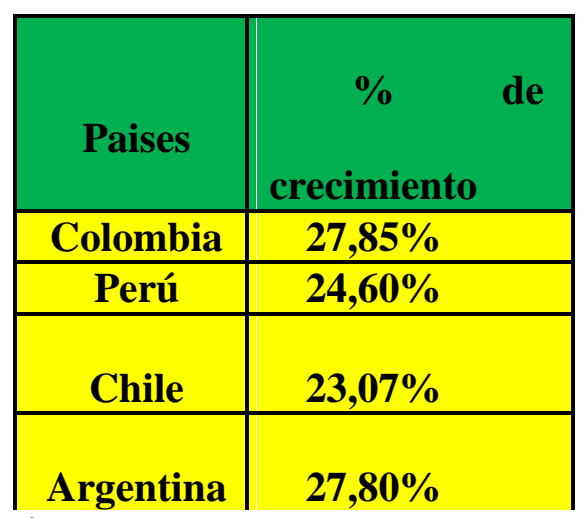

Cuadro No. 4. Países con mayor crecimiento en Sudamérica en el 2011 Fuente: Elaboración propia

En el Ecuador el parque automotor ecuatoriano cerró en el 2010 con más de 1.8 millones de vehículos matriculados, según datos oficiales. En el 2011 las ventas crecieron 5,84\% con relación al 2010. Se vendieron 139.893 unidades. De estos 62.585 fueron vehículos y 27.469 fueron camionetas.

En 2011 el sector registró el mejor pico de ventas de los últimos 4 años. En el primer semestre del 2012 se vendieron en el país 61.498 automotores, una caída del 12,65\% en comparación con el mismo periodo del año anterior. Las ventas de los autos con motores de entre 1.500 y 3.000 centímetros cúbicos (cc) cayeron en un 8,2\% entre enero y junio. La caída fue mayor para los vehículos de 3.000 cc en adelante, cerró el año con un 25,3\% (Diario El Universo, Economía, 2012)

De conformidad a la información obtenida a diciembre del año 2013 de parte del COMEX, la participación de las marcas muestra que Chevrolet se ubicó como la marca líder en ventas a nivel nacional con una 48\% de participación en el mercado (Diario El Universo, Economía, 2012), seguido de Kía con un 12\%, Hyundai $9 \%$ y el resto de marcas presentó una participación igual o inferior al $6 \%$. 
Un componente en la oferta de vehículos principalmente de vehículos livianos lo conforman las ensambladoras, que en el país son: General Motors Omnibus BB GM - OBB, Maresa, Aymesa y, Ciauto, todas ellas son productoras de vehículos de las marcas Chevrolet, Mazda, Kía y Great Wall respectivamente.

Estas ensambladoras presentan un alto nivel de tecnificación que les permite ser reconocidos por sus productos de calidad que incluso exportan, cifra que en enero y septiembre del 2014 ascendió a 6.212 unidades exportadas a Colombia en 59\% y Venezuela 39\%; Omnibus BB aportó con el 74\% de la producción nacional, Aymesa el 16\%, Maresa con el 10\% (Pro Ecuador, Dirección de Inteligencia Comercial e Inversiones, 2013)

La Asociación de Empresas Automotrices del Ecuador (AEADE) señaló que las restricciones a las importaciones de vehículos impuestas por el Consejo de Comercio Exterior (COMEX) a mediados del mes de junio ocasionarían una pérdida de ventas por 28.000 vehículos por un monto total de 240 millones, lo cual pondría en riesgo la estabilidad de muchas empresas y parte de las 14000 plazas de trabajo que dependen del sector. (Diario La Hora, País, 2015)

La AEADE señaló, que esta medida corresponde a las necesidades del Gobierno de estabilizar la balanza comercial, pero ellos creen que una restricción del 30\% podría ocasionar:

○ El cierre de empresas y la pérdida de empleos.

- La ampliación retroactiva de la medida ocasionaría desconfianza internacional y preocupación de los proveedores, por cuanto ya se colocaron y pagaron órdenes de vehículos que ahora no se pueden nacionalizar y cuyo reembarque ocasionaría grandes pérdidas económicas, pese a que ellas se hicieron base a las reglas vigentes en las Licencias de Importación.

- Las disposiciones del gobierno en las importaciones de vehículos son drásticas pues a diferencia de las reglas anteriores que solo determinaban cupos en dólares, la nueva medida establece cupos en dólares y en unidades, lo cual limita en mayor medida a las importaciones.

- Afectaría a negocios que dependen directa e indirectamente del sector automotriz. Además, provocaría un aumento de precios en los vehículos, ocasionando que sea más complicado renovar el parque automotor.

\section{Perspectivas futuras}

Partimos desde la premisa de que todos los impuestos generan distorsión en la economía, pues alteran los precios y las cantidades demandadas de los productos. Aun así, son necesarios porque financian gasto público que se justifica sea por un tema de eficiencia asignativa o de redistribución de los recursos. Con los tributos se financian servicios gubernamentales como la seguridad, justicia, educación y salud, (Senae, SRI, 2007) que si estuvieran privatizados en su financiación serían inaccesibles para gran parte de la población.

Para el Ecuador, un país petrolero y con escaza privatización en los servicios públicos y en los sectores estratégicos de la economía, la correcta medición del tamaño del sector público es: la recaudación de impuestos. (Diario El Universo, Noticias, 2015) 
Estos tributos han influido y se prevé que continúen ocasionando en un primer sentido, el decrecimiento de la balanza comercial, disminución de las plazas de trabajo en el sector privado principalmente, medidas de control en empresas, encarecimiento de vehículos y difícil acceso a la compra de vehículos en relación a costo.

\section{Conclusiones}

Las restricciones a las importaciones de vehículos, fueron medidas a favor de la balanza comercial ecuatoriana, es decir el cambio de la matriz productiva ha favorecido a ciertos sectores de la industria más no a todos. Las importaciones se vieron controladas y reducidas hasta el 2016 como medida de proteccionismo a la producción nacional, y aumentar la exportación de los productos ecuatorianos hacia el exterior.

Actualmente diferentes productos están en un proceso de ser liberados de las restricciones impuestas anteriormente, un ejemplo es el mercado automotriz, a través de la firma con del Tratado de libre Comercio con la Unión Europea, se cree que ciertos productos de este sector se beneficiarían y por ello sus costos bajarían para el consumo interno nacional.

La coyuntura del Ecuador no se ha mostrado favorable en los últimos años, ocasionando esto que el Estado evalúe las medidas de política económica y comercial que deberá tomar para controlar en algún sentido y elevar su dinamismo. Es así, que las restricciones de importación en vehículos responde a una contracción de política económica que permitiría frenar la salida de divisas esperando que eso retribuya positivamente en la balanza comercial y a su vez alivie el continuo déficit que ha mantenido durante los últimos años.

\section{Bibliografía}

Carlos Quisiguiña, Banco Central del Ecuador. (2016). Evolución del sector automotriz 2011 2015. Quito: Banco Central Del Ecuador.

Diario El Comercio, (9 de Enero de 2016). Precios de los vehículos con tendencia a la baja, pág. 1.

Diario El Comercio, Actualidad. (11 de octubre de 2013). Las ventas del sector automotor, estancadas, pág. 1.

Diario El Comercio, Actualidad. (05 de Enero de 2015). Ecuador restringe más las importaciones de autos este 2015, pág. 1.

Diario El Comercio, Economía. (13 de Julio de 2016). Demanda de créditos bancarios se redujo 6 , $8 \%$ el último año, pág. 1.

Diario El Universo, Economía. (16 de 06 de 2012). Comex impone cupos para importar carros y celulares, pág. 1. 
Diario El Universo, Noticias. (25 de Mayo de 2015). En 4 meses ya se vendió casi 40 \% del cupo de autos, pág. 1.

Diario El Universo, Noticias. (5 de enero de 2015). Importadores de vehículos piden revisar resolución, pág. 1.

Diario La Hora, Economía. (28 de enero de 2011). La importación de vehículos, con cupos, pág. 1.

Diario La Hora, País. (10 de Octubre de 2015). Cae empleo en sector automotriz, pág. 1.

El Comercio, actualidad. (30 de Septiembre de 2016). Ecuador eliminará los cupos de importación para el 2017, pág. 1.

Pro Ecuador, Dirección de Inteligencia Comercial e Inversiones. (2013). Análisis del sector automotriz. Guayaquil: Pro Ecuador.

Senae, SRI. (2007). Ley reformatoria para la equidad tributaria del Ecuador, publicada en el tercer registro oficial n. 242. Quito: Registro Oficial. 